\title{
Chapter 5 \\ Extensive Area of Topographic Anaglyphs \\ Covering Inland and Seafloor Derived Using \\ a Detailed Digital Elevation Model \\ for Identifying Broad Tectonic Deformations
}

\author{
Hideaki Goto
}

\begin{abstract}
Topographic anaglyph images were viewed with red-cyan glasses enabled to recognize topographic relief features easily. Anaglyphs produced from digital elevation model (DEM) data are a very effective technique to identify tectonic geomorphology. The aim of this paper was to introduce an extensive area of topographic anaglyph images produced from the 5-m-mesh and 10-mmesh inland DEM of Geospatial Information Authority of Japan, as well as the 1-s-mesh DEM on the seafloor. In this paper, we present two examples which show that the extensive area of anaglyph produced from combined detailed DEM is advantageous for identifying broad tectonic geomorphology near a coastal area, as well as in urban areas, to view "naked" topography exaggerated vertically. For instance, the NW-SE trending active flexure scarp on the Musashino surface to the north of Tokyo Metropolis has been identified by means of interpretation of these images. The tectonic deformation on the shallow seafloor near Kisakata has also been identified, where the emergence of the lagoon associated with the Kisakata earthquake (M7.0) of 1804 was recorded in the historical documents. When anaglyphs from detailed DEM are extensive and have emphasized vertical exaggeration, they are valuable for recognizing long-wave (one kilometer to several hundred meter scaled) deformations.
\end{abstract}

Keywords Active fault • Anaglyph • Tectonic geomorphology • Digital elevation model $\bullet$ Submarine topography $\bullet$ Kisakata $\bullet$ Musashino surface $\bullet$ Arakawa fault

\subsection{Introduction}

Topographic anaglyph images viewed with red-cyan glasses enables one to recognize the features of topographic relief in three dimensions. Anaglyphs produced from a digital elevation model (DEM) are very useful material for identifying

\section{H. Goto (ه)}

Hiroshima University, 1-2-3, Kagamiyama, Higashihiroshima, Hiroshima 739-8522, Japan e-mail: hgoto@hiroshima-u.ac.jp 
tectonic geomorphology. For instance, Goto and Sugito [1] revealed the discovery of several unknown inland active faults. Furthermore, Izumi et al. [2] revealed the distribution of submarine active faults along the eastern margin of the Japan Sea.

The Geospatial Information Authority of Japan (GSI) has published inland DEM data since the Basic Act on Promotion of Utilization of Geographical Information implemented in 2007. Goto [3] introduced anaglyph images to study inland geomorphology of Japan produced by the use of the 10-m-mesh DEM of GSI. However, high-resolution topographic anaglyph images covering both onshore and offshore areas have not been published because of a lack of detailed topographic data. Goto [4] has presented the topographic anaglyph images of the seafloor around Japanese Islands that were produced by using the 1-s-mesh (approximately $30 \mathrm{~m}$ ) DEM provided by the Japan Coast Guard.

The aim of this paper is to introduce extensive area of topographic anaglyph images produced from the 5-m-mesh and 10-m-mesh inland DEM of GSI, as well as the 1-s-mesh DEM (Goto [4]) on the seafloor. We identified active faults that have deformed alluvial plains, terrace surfaces, and seafloors by means of interpretation of these anaglyph images. Smaller fault scarps and fault-related broad deformations were newly identified in numerous inland sites as well as on the shallow seafloor. In this paper, we present two examples that show that the extensive area of topographic anaglyphs produced from combined detailed DEM is quite advantageous for identifying broad tectonic deformation near a coastal area, as well as in urban areas, when the "naked" topography is exaggerated vertically.

\subsection{Data and Methods}

Detailed DEM of the shallow seafloor obtained from direct data acquisition, such as acoustic prospecting/seismic profiling, is only available for a limited area of the coast. Thus, we reprocessed the 1-s-mesh DEM from digital bathymetric charts (M7000 series), with 1- to 2-m interval counters of the Japan Hydrographic Association (Goto [4]) (Fig. 5.1 A-D). Currently, the published area for inlands at 5-m-mesh DEM of GSI is still about $45 \%$ of the territory of Japan, as of November 2013. Therefore, the 5-m- and 10-m-resolution meshes that are at present the most detailed DEM open to the public were combined for inland geomorphology (Fig. 5.1 E, F).

We imported both inland and seafloor data that ranges from $2^{\circ}$ in longitude and $1^{\circ} 20^{\prime}$ in latitude to a Simple DEM Viewer ${ }^{\circledR}$. Then, we produced an anaglyph image to be overlapped on the base map of the black and white slope shading map and the black and white shaded relief map. We produced 65 map sheets under these conditions with less than 35,000 pixels on one side of each sheet. We also provided topographic anaglyph overlaid active fault maps (Nakata and Imaizumi eds. [5]) to facilitate a reexamination of active fault geomorphology (Fig. 5.2). 


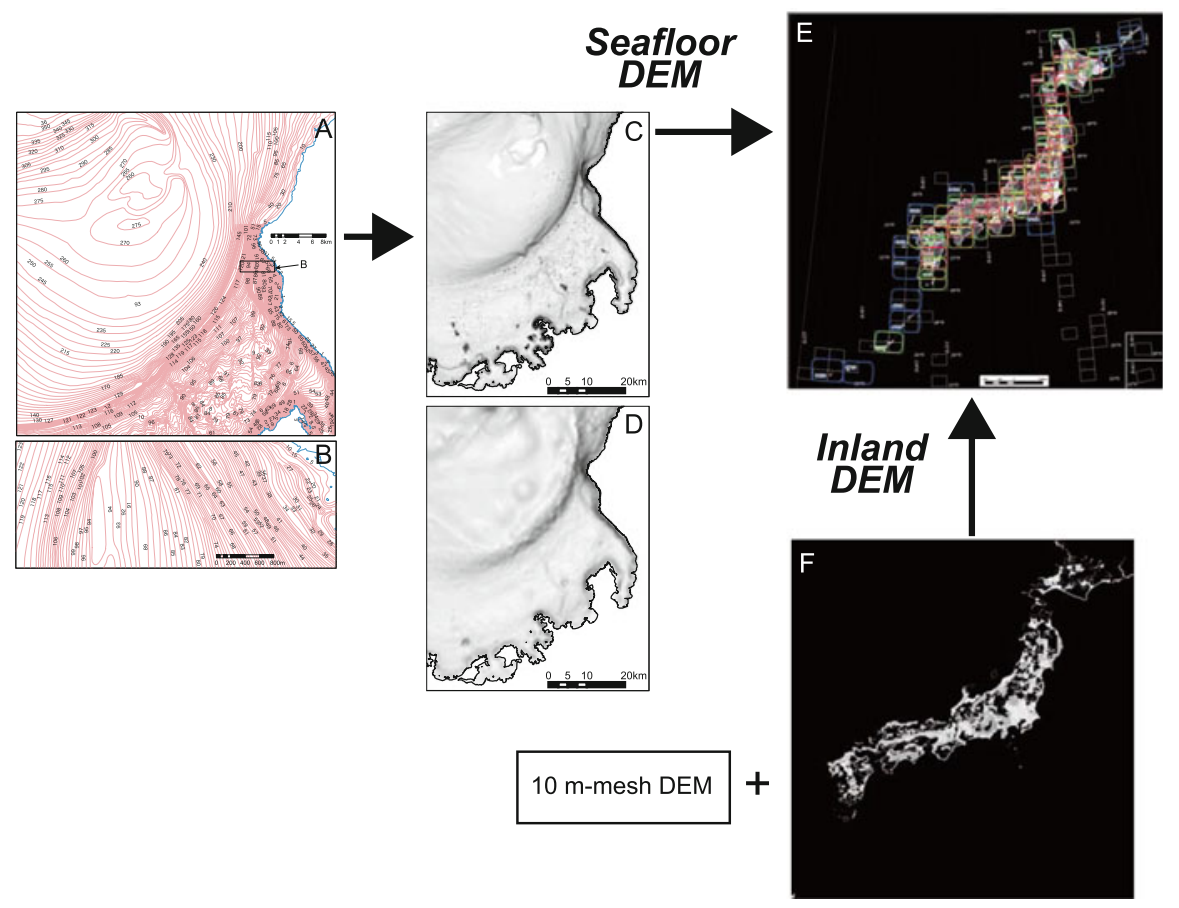

Fig. 5.1 The data processing flow. Box $A$ is a part of the bathymetric chart (M7012) provided by the Japan Coast Guard from which we reprocessed 1-s-mesh DEM. The interval of counters on the chart is different from place to place. The distance between counters is under $50 \mathrm{~m}$ as shown in the $B o x B$. Anaglyph $(C)$ produced from 1-s-mesh (ca.30 m) DEM reprocessed from bathymetric chart (M7012) is quite finer than anaglyph $(D)$ produced from 500-m-mesh DEM (J-EGG500). The published area of 5-m-mesh DEM of GSI is limited as of November $2013(F)$. The 65 sheets of detailed topographic anaglyph within the range of $2^{\circ}$ in longitude and $1^{\circ} 20^{\prime}$ in latitude are produced $(E)$

\subsection{Fault-Related Broad Deformations in an Urban Area Identified on the Anaglyph}

Airborne LiDAR (light detection and ranging) surveying has been developed to detect detailed geomorphic features (e.g., Nelson et al. [6]). Airborne LiDAR has the capability of revealing the "bare earth," with vegetation and buildings removed, because the ground emits a laser pulse that can be separated from canopy returns through a filtering process. Thus, these data can be used to explore quantitatively the characteristics of tectonic geomorphology (e.g., Arrowsmith and Zielke [7]). The data also revealed small-scale fault scarps in the urban area (e.g., Kondo et al. [8]) as well as on the mountain slopes beneath the dense forest vegetation (e.g., Lin et al. [9]). However, fault-related broad deformations were invisible on the usual topographical maps (slope shade map, hill shade map, and contour map), even if airborne LiDAR data was adopted. Topographical anaglyphs produced from 


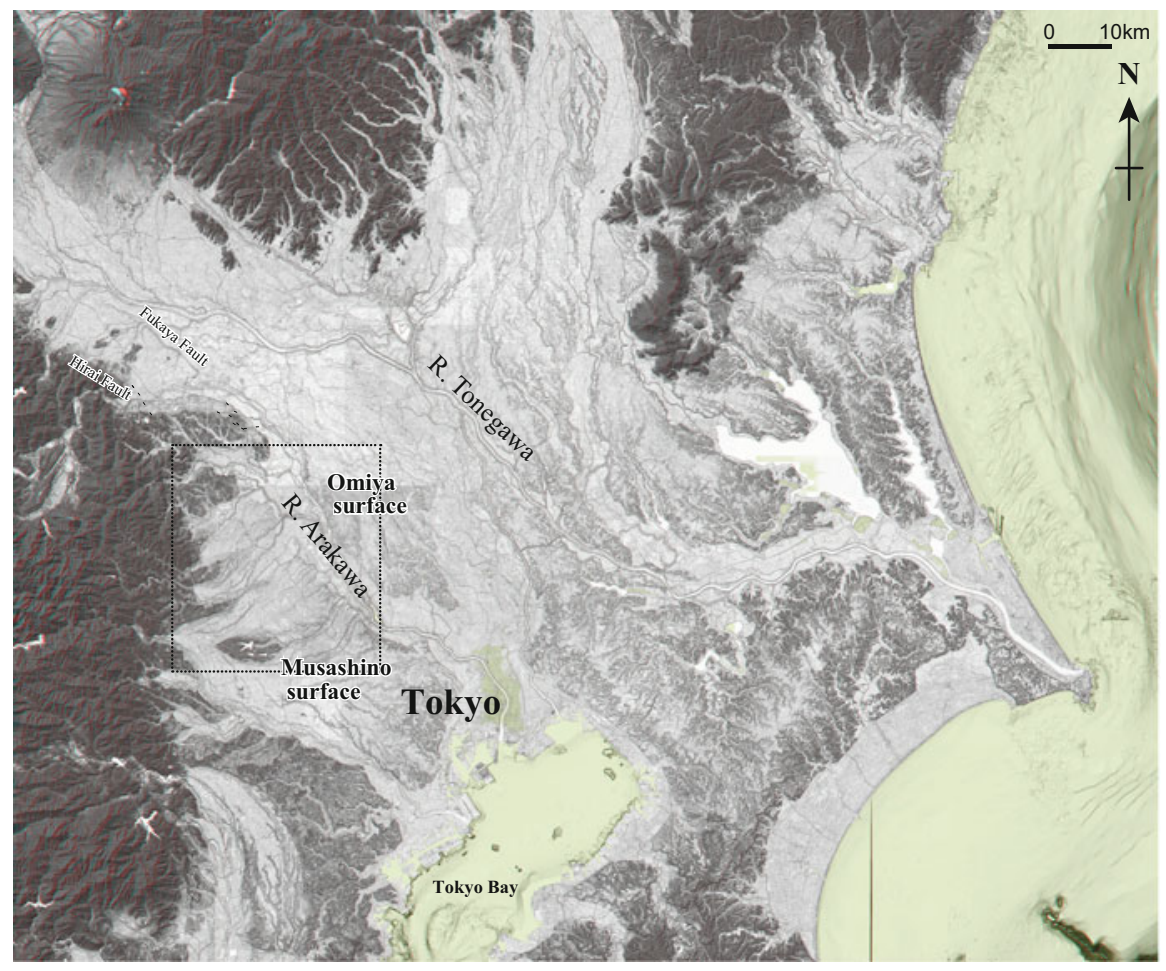

Fig. 5.2 Extensive area of a topographic anaglyph around Tokyo Metropolis. It is one of the 65 sheet maps produced from 5-m-mesh and 10-m-mesh DEM of inland of GSI and 1-s-mesh (ca.30 m) DEM of the seafloor. The dotted-line box indicates the area of Fig. 5.3

DEM based on LiDAR data are easily observed in three dimensions like stereopaired aerial photographs, when wearing red-cyan glasses. Broad deformation related to recent faulting could be identified on the extensive area of the topographic anaglyph because it can be emphasized in vertical exaggeration and rescaled on a PC monitor. Here, newly identified tectonic geomorphology to the north of Tokyo Metropolis is shown as an example (Fig. 5.2).

The Arakawa River flows from the Kanto Mountains into Tokyo Bay through the northwestern part of the Kanto basin, where the Pleistocene terraces are well developed. The terraces situated on the left and right banks in the middle reaches of the river are called the Omiya surface and the Musashino surface, respectively (Fig. 5.2). Kaizuka [10] suggested that the northern part of the Musashino surfaces was inclined to the northeast, compared to the east and south slope of this surface, based on an analysis of a contour line map. For this reason, the NW-SE trending east side up the Arakawa fault that is buried beneath the alluvial plain would be extended along the southwestern side of the Omiya surface (Kaizuka [10]). On the contrary, Hirouchi [11] supposed that the displacement of surfaces across the Arakawa fault was not observed, based on the topographic profiles on the 


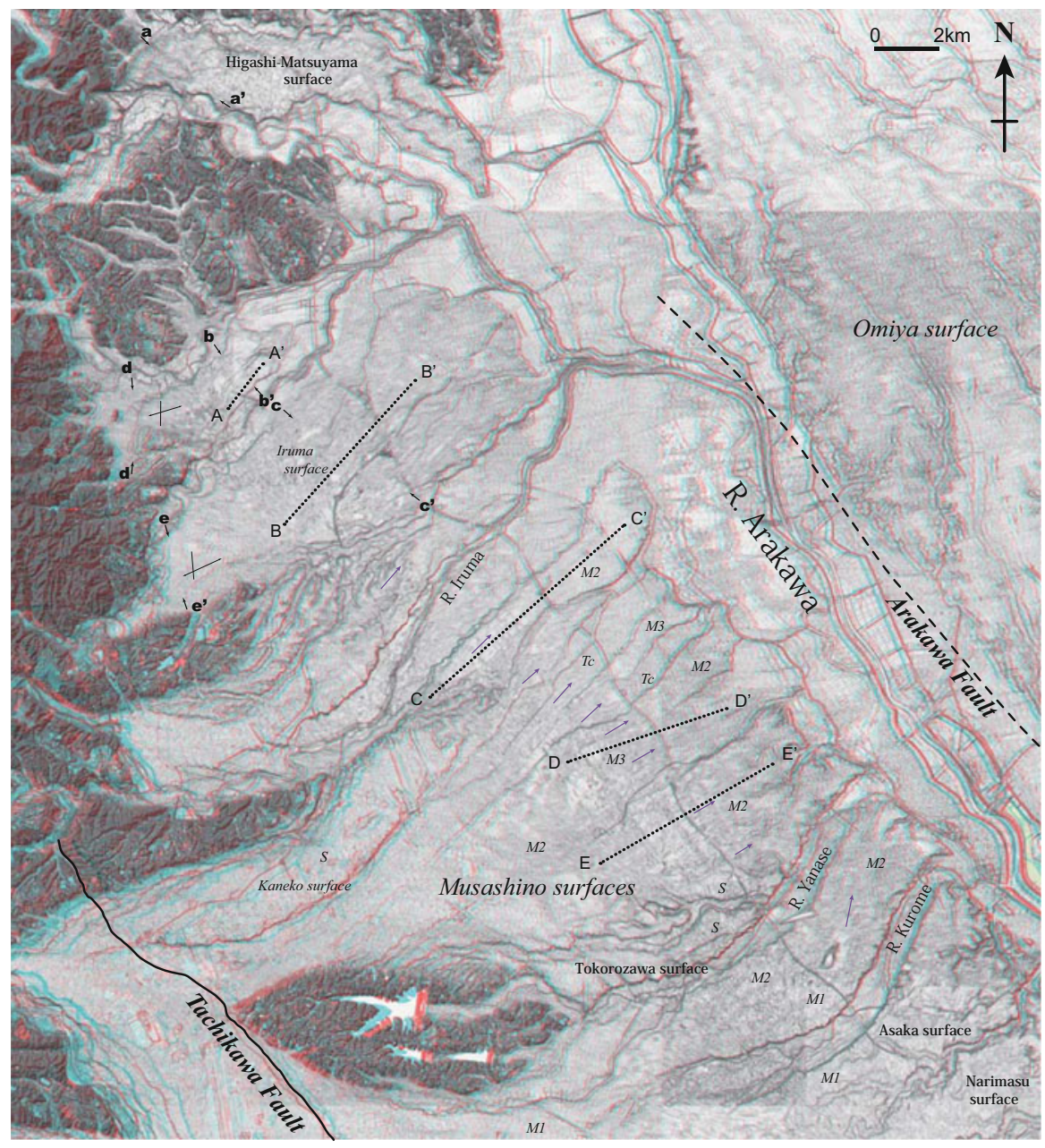

Fig. 5.3 Deformation of the Musashino surfaces to the north of Tokyo Metropolis showing on the detailed topographic anaglyph. The purple arrows indicate the flexure scarps on the Musashino surface (Musashino flexure zone). The newly identified small scarps related to recent faulting are marked with small arrows $\left(a-a^{\prime}\right.$ to $\left.e-e^{\prime}\right)$. The small scarps $\left(b-b^{\prime}\right.$ to $\left.c-c^{\prime}\right)$ on this figure are called the Tsurugashima fault. The active fault lines depicted in the previous paper show black lines

Musashino surface and Omiya surface. The Headquarters for Earthquake Research Promotion [12] assessed that the east-side-up buried fault was not distributed along the Arakawa River. Therefore, the geomorphological evidence of tectonic crustal movement has not been clarified in this area.

When we interpreted the detailed topographic anaglyphs of this area, the westside-up several-hundred-meter-long convex slopes were found on the northern part of the Musashino surfaces (Fig. 5.3). These scarps must have been flexure scarps related to recent faulting, because these NW-SE trending scarps were detected at 

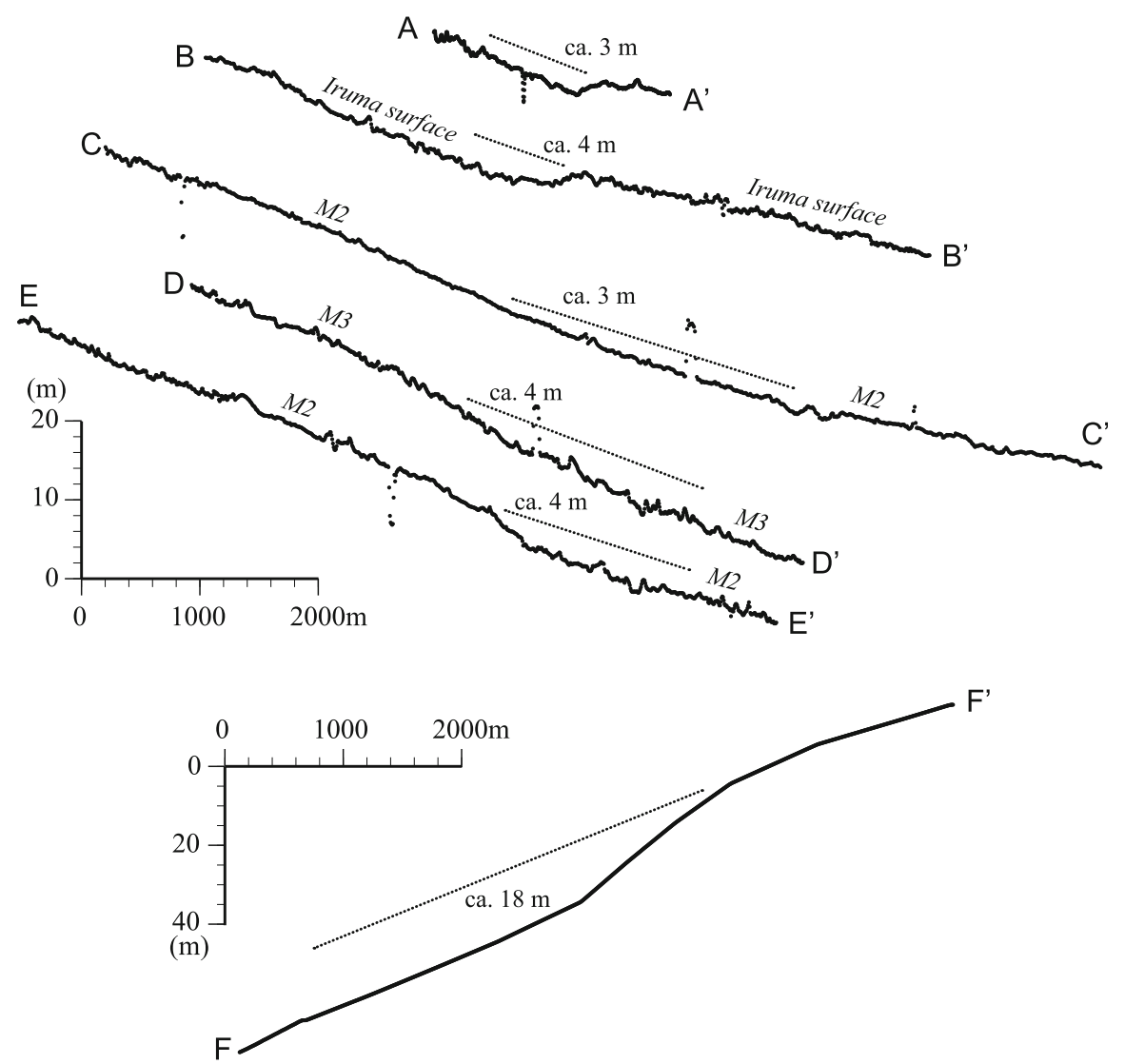

Fig. 5.4 Topographic profiles across the Musashino flexure zone and the Tsurugashima fault, based on the DEM. The measured lines are shown in the Figs. 5.3 and 5.5

different heights of Musashino surfaces (M2, M3) and Tachikawa surface (Tc) (Figs. 5.3 and 5.4) and are designated here as the Musashino flexure zone.

To the northwest of this zone, the small fault scarps facing the mountain (the Tsurugashima fault) were also newly identified on the Iruma surface (Fig. $5.3 b-b^{\prime}$, $c-c^{\prime}$ ). Other small fault scarps on the surfaces are also detected using the anaglyphs (Fig. $5.3 a-a^{\prime}, d-d^{\prime}, e-e^{\prime}$ ). The Musashino flexure zone extends as a series of the Tsurugashima fault although showing the reverse sense of the downthrown side. The upthrown side along the strike-slip fault is, in general, located on the relative strike-slip motion side of the faulted block (e.g., Nakata and Goto [13]). Thus, the active tectonic movement forming these features may have a left-lateral component, although at present we failed to find any geomorphological evidence for strike-slip faulting along these scarps. Furthermore, a series of the Musashino flexure zone and the Tsurugashima fault might relate to the Hirai left-lateral fault system situated to the northwest along the foot of Kanto Mountain (Fig. 5.2). 


\subsection{Coastal Geomorphology on the Anaglyph}

Coastal geomorphology, such as the distribution of the Holocene marine terraces and differences in the heights of the shoreline of the Pleistocene marine terraces along the coastline, could be a clue for not only sea-level changes but also active tectonics (Earth crustal movements). However, the number of published geomorphologic reports is limited because of the lack of extensive topographic maps covering both the onshore and offshore area seamlessly. One of the technical methods to overcome such difficulties is to make seamless anaglyph images as shown in this paper. Such an approach to tectonic topography including for unknown active faults come to light around the coastline. Here, submarine active tectonic geomorphology off Kisakata, Akita Prefecture, is shown as an example, in order to indicate the usefulness of the anaglyph images for better understanding of active tectonics in a coastal region.

Tectonic deformation on the shallow seafloor has been newly identified near Kisakata, where the emergence of the lagoon associated with the Kisakata earthquake (M7.0) of 1804 was recorded in the historical documents (Usami [14]). According to the historical pictures and documents, the hummocky hills caused by the debris avalanche from Mt. Chokaisan were distributed in the lagoon around Kisakata before the earthquake. We could observe so many different sizes of hills to the northwestward of Mt. Chokaisan on the anaglyph (Fig. 5.5). We could also recognize the paleo-lagoon in Kisakata by the scattered small hills surrounding the flat plains.

To the 10-14 km west of Kisakata and Yuri-Honjo, the NS trending continental shelf slope divides the Tobishima basin from the continental shelf. Although several anticlinal axes of deformed Quaternary sediment are estimated to be striking parallel to this slope beneath the continental shelf (Osawa and Suda [15]), no surface evidence of tectonic deformation has not been recognized off Kisakata.

However, the NNE trending steep flexure slope on the continental shelf along the coastline neighboring to the paleo-lagoon is illustrated in the seamless anaglyph image (Fig. 5.5). The slope extends for at least $15 \mathrm{~km}$ in the middle of the $10-\mathrm{km}$ wide shallow seafloor, with a gentle sloping toward WNW. These topographic features are consistent with subsurface structure recorded by the acoustic exploration (Geological Survey of Japan [16]). The active anticline axis parallel to the coastline was identified in the south extension of this slope by seismic reflection profiling (Horikawa et al. [17]). This long-wave deformation would most likely be caused by a subsurface fault, which is the most probable candidate for the source of the 1804 earthquake, because the uplifted area associated with the earthquake (Usami [14]) is parallel to this deformation. 


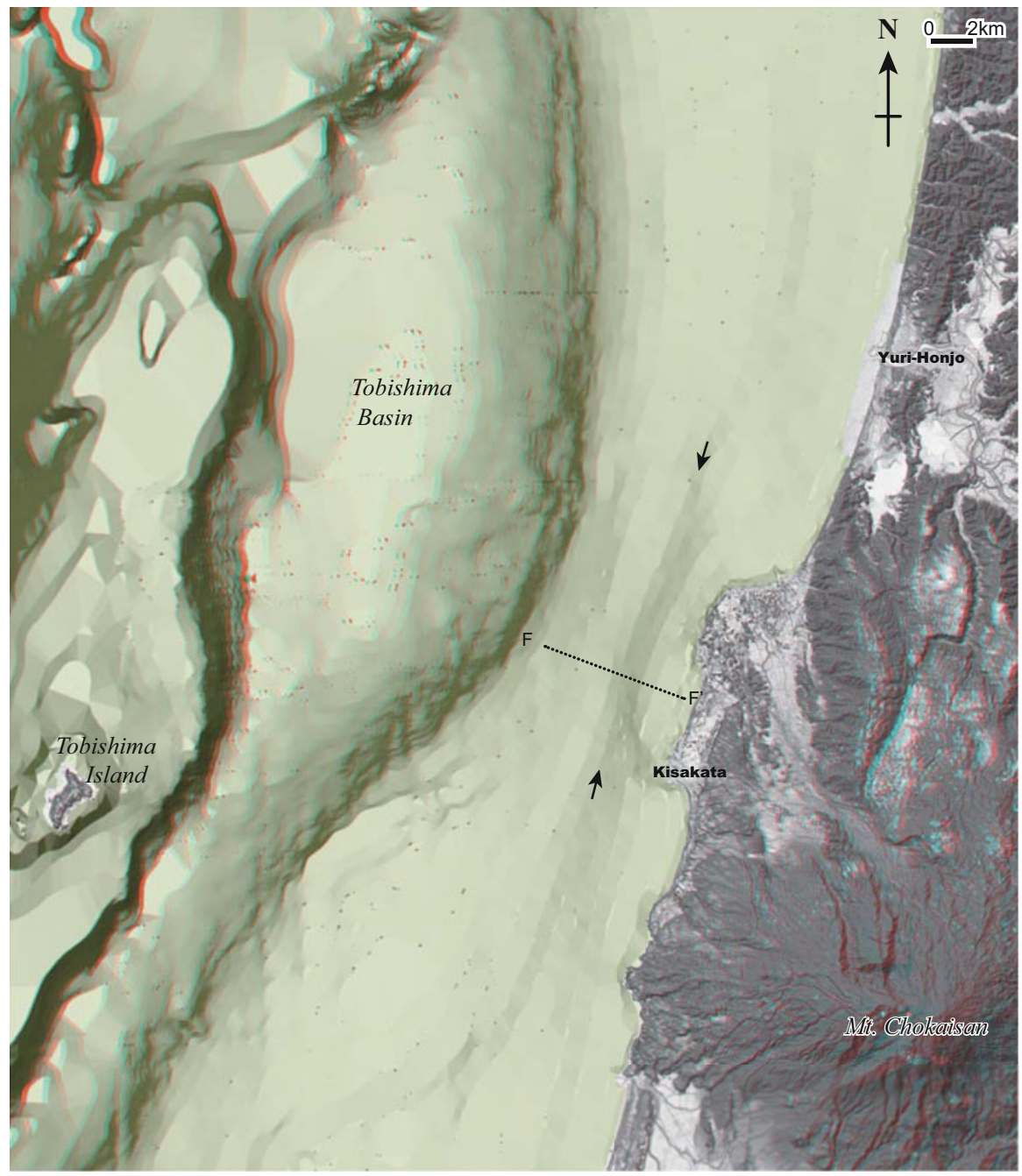

Fig. 5.5 An anaglyph showing the broad deformation on the shallow seafloor near Kisakata, Akita Prefecture. The newly identified broad scarps related to recent faulting are marked with small arrows

\subsection{Conclusions}

We produced detailed topographic anaglyphs from inland DEM measured by LiDAR data as well as 1-s-mesh DEM from digital bathymetric charts. We could easily observe macro- to micromorphology in three dimensions on a seamless anaglyph image covering both onshore and offshore using red-cyan glasses. Although it is difficult to detect a broad deformation related to recent faulting on any conventional maps, we could easily recognize such a deformation on anaglyphs 
when it is emphasized in vertical exaggeration. Future research combining seamless anaglyph images and well-trained personnel, to identify tectonic geomorphology around nuclear power plant sites, will provide important datasets for seismic safety evaluation.

\subsection{Acknowledgment}

My heartfelt appreciation goes to Dr. Takashi Nakata, Professor Emeritus at Hiroshima University whose comments and suggestions were of inestimable value for my study. I am also indebted to Yoshiaki Katayanagi, who kindly modified his software (Simple DEM viewer) for our analysis. I have also had the support and encouragement of Prof. Mitsuhisa Watanabe, Prof. Takashi Kumamoto, Prof. Yasuhiro Kumahara, Prof. Nobuhisa Matsuta, Dr. Nobuhiko Sugito, and Prof. Takahiro Miyauchi. This work was funded by JSPS KAKENHI grant numbers 25350428 and 23240121.

Open Access This chapter is distributed under the terms of the Creative Commons Attribution Noncommercial License, which permits any noncommercial use, distribution, and reproduction in any medium, provided the original author(s) and source are credited.

\section{References}

1. Goto H, Sugito N (2012) Fault geomorphology interpreted using stereoscopic images produced from digital elevation models. E-journalGEO 7:197-213. http://dx.doi.org/10.4157/ejgeo.7. 197 (in Japanese with English abstract)

2. Izumi N, Nishizawa A, Hirouchi D, Kido Y, Nakata T, Goto H, Watanabe M, Suzuki Y (2014) 3D bathymetric image of the eastern margin of the Sea of Japan based on 3-second grid DEM. Rep Hydrogr Oceanogr Res 51:127-139. http://www1.kaiho.mlit.go.jp/GIJUTSUKOKUSAI/ KENKYU/report/rhr51/rhr51-TR10.pdf (in Japanese with English abstract)

3. Goto H (2012) Anaglyph images of Japan produced from digital elevation model: explanatory text and sheet maps. Hiroshima University Studies Graduate School of Letters, Special Issue 72: 69p. http://ir.lib.hiroshima-u.ac.jp/00034345 (in Japanese with English abstract)

4. Goto H (2013) Submarine anaglyph images around Japan Islands based on bathymetric charts: explanatory text and sheet maps. Hiroshima University Studies Graduate School of Letters, Special Issue 72: 69p. http://ir.lib.hiroshima-u.ac.jp/00035603 (in Japanese with English abstract)

5. Nakata T, Imaizumi T (eds) (2002) Digital active fault map of Japan. Tokyo Press, Tokyo, 68 p (in Japanese with English abstract)

6. Nelson AR, Johson SY, Kelsey HM, Wells RE, Sherrod BL, Pezzopane SK, Bradley L, Koehler RD, Buchnam RC (2003) Later Holocene earthquakes on the Toe Jam Hill Fault, Seattle fault zone, Bainbridge Island, Washington. Geol Soc Am Bull 115:1388-1403

7. Arrowsmith JR, Zielke O (2009) Tectonic geomorphology of the San Andreas Fault zone from high resolution topography: an example from the Cholame segment. Geomorphology 113: $70-81$ 
8. Kondo H, Toda S, Okumura K, Takada K, Chiba T (2008) A fault scarp in an urban area identified by LiDAR survey: a case study on the Itoigawa-Shizuoka Tectonic Line, central Japan. Geomorphology 101:731-739

9. Lin Z, Kaneda H, Mukoyama S, Asada N, Chiba T (2013) Detection of subtle tectonic geomorphic features in densely forested mountains by very high resolution airborne LiDAR survey. Geomorphology 182:104-115. doi:10.1016/j.geomorph.2012.11.001

10. Kaizuka S (1957) Deformation of the diluvial upland Musashino, and its significance on the movements of Kanto tectonic basin. Quat Res 1:22-30 (in Japanese)

11. Hirouchi D (1999) A Reconsideration of the activity of the Arakawa fault deduced from the longitudinal profiles of Late Quaternary terraces in the Musashino and Omiya uplands. Geogr Rev Jpn 72:335-344 (in Japanese with English abstract)

12. The Headquarters for Earthquake Research Promotion (2004) Long-term evaluation of the Arakawa fault. http://www.jishin.go.jp/main/chousa/04aug_arakawa/index.htm (in Japanese)

13. Nakata T, Goto H (1998) New geometric criteria for active fault segment; Fault branching and dip-slip distribution pattern along strike-slip faults. Act Fault Res 17:43-53. http://ir.lib. hiroshima-u.ac.jp/00025450 (in Japanese with English abstract)

14. Usami T (2008) Materials for comprehensive list of destructive earthquakes in Japan, Revised and enlarged edn. Tokyo University Press, Tokyo (in Japanese). http://www.utp.or.jp

15. Osawa A, Suda Y (1980) Geological map of Japan 1:200,000. Geological Survey of Japan, Akita/Oga

16. Geological Survey of Japan (2015) Database of offshore geologic structure. https://gbank.gsj. jp/marineseisdb/index_E.html

17. Horikawa H, Okamura Y, Murakami F (2011) Seismic reflection profiling of the shallow structure of the Sakata-oki Uplift, Northeast Japan. Ann Rep Act Fault Paleoearthq Res 11: 83-96 (in Japanese with English abstract) 